\title{
New methods in genotype diagnostics of small- fruit crops for intensive gardening
}

\author{
Olga Panfilova ${ }^{l *}$, Mikhail Tsoy ${ }^{l}$, Olga Kalinina $^{l}$, Sergey Knyazev ${ }^{l}$ \\ ${ }^{1}$ Russian Research Institute of Fruit Crop Breeding (VNIISPK), Zhilina, Orel district, Orel region, \\ Russian Federation
}

\begin{abstract}
Physiological and morphological studies of red Russian and foreign breeding red currant varieties were carried out for establishing intensive plantings and introduction. Varieties Dana, Niva, Vika, Hollandische Rote are yielding, highly resistant and promising for introduction and industrial cultivation, during dry periods they are able to regulate metabolism through changing indicators of water balance (water deficit, fractional composition of water) and photosynthetic apparatus of leaves (leaf lamina area). Using Natali, Shchedraya and Jonkheer Van Tets varieties in production is possible with application of artificial irrigation. Selyanochka variety is most affected by weather conditions and is recommended to be grown in temperate climate area. Physiological and morphological methods of research allow to diagnose the genotypes resistance of garden crops to growing period abiotic factors at the early stages of plant development, they are confirmed by field observations and are promising in diagnosis for establishing intensive gardens and berryfields.
\end{abstract}

\section{Introduction}

One of the promising directions of world horticulture development is the introduction of intensive gardens and berry-fields, for which technological, highly resistant, earlymaturing, fruitful, profitable varieties are required; those varieties must have high commercial and consumer qualities, providing a year-round supply of fresh fruit to the population. Recently, due to climate change, there has been a clear trend towards reducing the resilience of genotypes, which primarily affects yields, quality of products and eventually the economy of the region $[1,2]$.

Adaptability of fruit and berry crops to adverse environmental conditions is one of the main characteristics that determine their economic value and the efficiency of their cultivation in a particular area. Reduced resistance to changing environmental factors has been one of the main reasons for the decline in production plantings of berry crops. Favorable conditions for growth of species and varieties of red currant are zones with moderate temperature and humidity.

\footnotetext{
*Corresponding author: us@vniispk.ru, olga 280682@mail.ru
} 
Frequent droughts during the growing season are the main cause of lower yields and deterioration of plant biological condition (necrosis, defoliation and fruit cast, apoplexy) $[3,4]$. The problem of plant resistance to stress temperature influences is significant and is among the fundamental problems in biology.

In this regard, the search for new methods and techniques that allow to diagnose the resistance of genotypes to stress factors in the early stages is of high relevance. Physiological-biochemical research methods are promising methods in assessing adaptability to drought and elevated temperature [5,6]. In some fruit and berry crops (apple trees, grapes, currants) during the period of drought there were changes in the water balance, morphological leaf structure: decrease in the overall leaf water content, inherent water increase and reduction of leaf lamina area $[3,4,7,8]$.

The purpose of this work is to assess the features of the water regime and morphological structure of the leaf of currant varieties of foreign and domestic selection for establishing industrial (intensive) plantings and introduction.

\section{Materials and Methods}

The research was carried out in the Department of breeding and strain investigation of berry crops of the Russian Research Institute of Fruit Crops Breeding in 2014 - 2016. The Institute is located in the central part of the Middle Russian upland; climate is moderately continental. Over the years of study, weather conditions varied greatly. The hydrothermal coefficient (HTC) calculated according to Selyaninov's formula was used to estimate the aridity of the growing periods [9]

$$
H T C=\sum R / 0.1 \sum T \geq 10^{\circ} \mathrm{C}
$$

$\Sigma \mathrm{R}$ - the amount of precipitation per month;

$\Sigma \mathrm{T}$ - the sum of air temperatures greater than $10^{\circ} \mathrm{C}$.

The most arid was $2014\left(\mathrm{HTC}=0.45 ; 0.46 ;+30.2 \ldots+32.2^{\circ} \mathrm{C}\right)$. High water availability against the background of increased temperatures was from May to July 2015 (HTC =1.03; $\left.1.94 ;+28.4 ;+32.3^{\circ} \mathrm{C}\right)$. Vegetation period of 2016 by hydrothermal conditions was intermediate $\left(\mathrm{HTC}=0.82 ; 0.71 ;+26.6 ;+28.2^{\circ} \mathrm{C}\right)$.

Objects of study were 8 varieties of red currant: Vika, Niva, Dana, Selyanochka (selections of Russian Research Institute of Fruit Crops Breeding), Natali (selections of Russian Horticultural Institute for Breeding, Agrotechnology and Nursery), Shchedraya (VIR selections), Hollandische Rote (or Prins Albert), Jonkheer Van Tets (Western Europe). The origin of the varieties is presented in Table 1.

Table 1. Genetic origin of varieties.

\begin{tabular}{|c|c|}
\hline Variety & Origin \\
\hline Jonkheer Van Tets & Faya plodorodnaya $\times$ London's Market \\
\hline Hollandische Rote & Ribes rubrum L. $\times$ Ribes petraeum Wulf \\
\hline Natali & R. vulgare Lam. $\times$ Ribes rubrum L. $\times$ Ribes petraeum Wulf \\
\hline Shchedraya & Faya plodorodnaya $\times$ Houghton Castle \\
\hline
\end{tabular}




\begin{tabular}{|c|c|}
\hline Niva & Minnesota $71 \times$ Chulkovskaya \\
\hline Vika & Chulkovskaya $\times$ Red Lake \\
\hline Dana & Rote Spatlese $\times$ Jonkheer Van Tets \\
\hline Selyanochka & Rote Spatlese $\times$ Red Lake \\
\hline
\end{tabular}

Drought-resistance of leaves was studied according to indicators of water content, water deficiency.

The water content of the leaf tissue was determined by drying it to a constant weight in the drying cabinet at $\mathrm{t}=+105^{\circ} \mathrm{C}$ and determined according to the formula [10]:

$$
K=\frac{A}{B} \cdot 100
$$

$\mathrm{K}$ - leaf water content, \%; A - dry weight, g; B - wet weight, g

Water deficiency - by full saturation of leaves with water [11]

$$
W_{g}=\frac{\left(M_{1}-M_{3}\right) \cdot\left(M_{1}-M_{3}\right)}{\left(M_{2}-M_{3}\right)} \cdot 100
$$

Wg - water deficiency, \%; $\left(M_{2}-M_{3}\right)$ - amount of water saturating leaves, $g$; $\left(M_{1}-M_{3}\right)$ initial water content in leaves, $g ., M_{1}$ - leaf mass before saturation with water, g., $M_{2}$ - leaf mass after saturation with water, g., $\mathrm{M}_{3}$-dry weight, $\mathrm{g}$.

The content of free and inherent water - according to the methodical recommendations of Okuntsov - Marinchik [12]. Concentration of sucrose solution 30\%.

The amount of inherent and free water was calculated by the formulas:

$$
\begin{gathered}
Q=\frac{100\left(D_{0}-D_{1}\right) \cdot m}{D_{1} \cdot m_{1}} \\
Q_{1}=K-Q
\end{gathered}
$$

Q- amount of free water, $\%, \mathrm{D}_{0}$ - percent of sucrose in the initial solution; $\mathrm{D}_{1}$ - percent of sucrose in the experimental solution; $\mathrm{m}$ - mass of the solution, $\mathrm{g} ; \mathrm{m}_{1}$ - leaf weight, $\mathrm{g}$.

Q1- amount of inherent water, \%; K - leaf water content, \%;

Leaf area was determined by the cuttings method. An average sample of 8-10 leaves (N) was taken, their wet weight $\left(\mathrm{M}_{1}\right)$ was determined. Leaves were placed on one another and cuttings were made using a drill of a certain diameter, 5-10 pieces on one leaf. Cuttings were taken so that both laminas and primary ribs were included in the sample. The mass of all raw cuttings is determined $\left(\mathrm{M}_{2}\right)$.

The area of leaves from one plant was determined by the formula [13]:

$$
S=\frac{M_{1} \cdot q \cdot \pi d^{2}}{M_{2} \cdot N \cdot 4 \cdot 10000}
$$


$\mathrm{S}$ - area of leaves of one plant, $\mathrm{m}^{2} ; \mathrm{M}_{1}$ - mass of leaves in the sample, $\mathrm{g} ; \mathrm{M}_{2}$ - cuttings mass, g; q - number of cuttings, pcs.; $\mathrm{N}$ - quantity of leaves in sample, pcs.; d - drill diameter, $\mathrm{cm} ; \pi=3.14$

Experiments were carried out in May and July in 6-time repetition. Leaf specimens were sampled from the middle part of the bush from annual shoot increments.

Dispersion, correlation analysis of the 0.05 significance level was carried out using the Microsoft Excel 2010 software package [14]. The influence degree of the variety and conditions of the growing period on physiological and morphological signs was estimated using the coefficient of indicator variation (CV). The value of $\mathrm{CV} \leq 10 \%$ is a weak indicator variability, at $10 \% \leq \mathrm{CV} \leq 20 \%$-average and $\mathrm{CV}$ more than $20 \%$ - high.

The Student criterion ( $\mathrm{T}$ ) at the indicator significance of $\mathrm{P} \leq 0.05$ was used to assess the indicator significance level.

\section{Results and Discussion}

\subsection{Water regime}

Plant adaptation is due to different mechanisms: physiological, genetic, biochemical, anatomic-morphological, cytological. The effects of adaptability (plasticity) to certain factors of the region are often recorded even by external manifestations [15]. In the works of N. S. Repkina [16], Sękara et al. [17], O.V. Panfilova et al. [18] it is stated that adaptation mechanisms are individual with respect to a certain influence factor. Some scientists justify physiological, biochemical processes with the water supply of plants. In the absence of water, metabolism is disrupted, which affects the growth and development of plants, their productivity [2, 19-21].

In studies conducted on different varieties of red currant, the lability of the total water content from both genotype, season and month of study is shown. Weather conditions of the growing periods of 2015 and 2016 were the most favorable for the growth and development of the varieties studied, the water content in the leaves ranged from 62.35 to $78.36 \%$. By the first decade of July (1-10.07) 2014-2016, there was a sharp decrease in the content of total water in the varieties studied, which is not only due to weather conditions of these periods, age of the leaf, but also due to the high need for water supply of plants for the formation of berries (Figure 1).

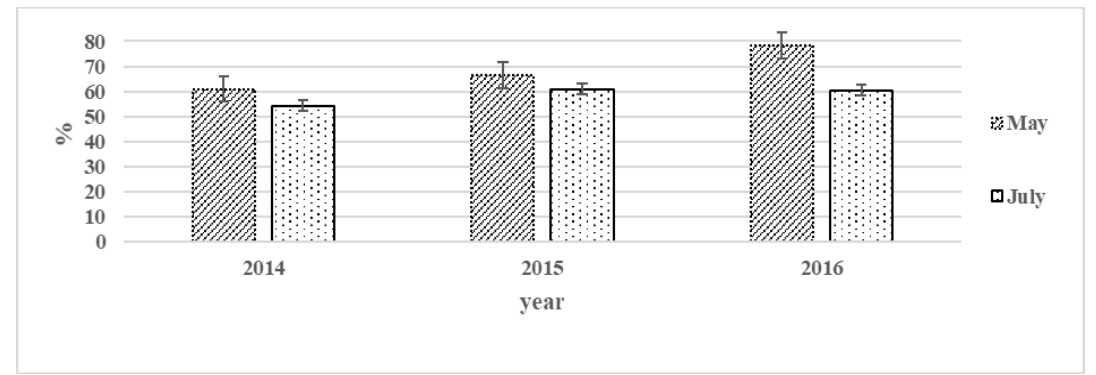

Fig. 1. Leaf water content of red currant varieties

Air and soil drought in 2014 resulted in a significant decrease in water content to 54.01 $57.23 \%$. At the same time, the varieties Selyanochka, Vika, Shchedraya, Jonkheer Van Tets showed a maximum decrease of up to $15-20 \%$ in comparison with favorable periods. 
In varieties Shchedraya, Selyanochka, Jonkheer Van Tets, there is a strong fruit cast (up to $25-30 \%$ ), which is a consequence of external manifestation of moisture deficiency. Similar pattern was noted by researchers in apple trees, red and black currants $[3,4,22]$. The decrease in water content in 2014 led to an increase in the value of water deficiency in comparison with favorable periods. However, most of the varieties studied were characterized by low water deficiencies (less than 15\%). This level did not lead to significant disruptions in plant growth and development processes.

Some researchers attribute the mechanism of plants drought adaptation not to the total water content in leaves, but to its fractional composition - the amount of free and inherent water. Free water provides the course intensity of a number of physiological processes, and the inherent water contributes to increasing the resistance of plants to abiotic stressors $[2,4$, 7, 19, 22, 23].

The obtained content results of free and inherent water in the leaves of varieties prove the variability of this indicator ( $\mathrm{CV}$ more than 20\%), i.e. strong dependence on meteorological conditions. The values of the Student criterion $(\mathrm{T})$ were valid at the significance of the indicator $\mathrm{P} \leq 0.05$ (Table 2).

Table 2. The ratio of inherent water to free varieties of red currant

\begin{tabular}{|c|c|c|c|c|}
\hline variety & 2014 & 2015 & 2016 & CV \\
\hline Vika & 1.27 & 0.81 & 0.61 & 30.82 \\
\hline $\begin{array}{c}\text { Hollandische } \\
\text { Rote }\end{array}$ & 1.55 & 1.80 & 0.86 & 17.52 \\
\hline Dana & 1.82 & 0.87 & 0.51 & 51.81 \\
\hline $\begin{array}{c}\text { Jonkheer Van } \\
\text { Tets }\end{array}$ & 0.99 & 1.85 & 0.99 & 31.76 \\
\hline $\begin{array}{c}\text { Natali } \\
\text { Niva }\end{array}$ & 1.38 & 0.71 & 0.69 & 34.60 \\
\hline Selyanochka & 0.90 & 0.47 & 0.75 & 29.66 \\
\hline Shchedraya & 1.09 & 0.62 & 0.73 & 24.68 \\
\hline T & 3.14 & 4.02 & 4.40 & \\
\hline
\end{tabular}

T - Student criterion, CV - Variation factor, $\%$

In 2014, which was arid in hydrothermal conditions, the coefficient values of the inherent water to free water ratio were the highest, this indicator should be considered as one of the mechanisms of protective - adaptive reaction of varieties to negative factors of the external environment. Changing the ratio of water forms allowed to maintain resistance 
to temperature stress and a certain yield under the prevailing conditions. At the same time, Selyanochka, Shchedraya, Jonkheer Van Tets were unable to ensure optimal functioning of basic physiological processes against the background of other studied varieties, the content of inherent water was low, water deficit value (more than 15\%) - high, which was also the cause of fruit cast, leaves edge necrosis, reduction of the number of reproductive buds for the yield of the future year and a small increase in annual shoots $(5-8 \mathrm{~cm})$.

\subsection{Leaf morphology}

Increasing the productivity of berry crops is possible only on the basis of studying the characteristics of the assimilation apparatus, on which the yield depends. The size of the assimilation surface and leaf structure are an important factor in plant photosynthetic activity.

Studies of morphological and anatomical features of leaves of red currant varieties have shown that separate morphological indicators of leaves (shape, venation pattern) depend on biological (genetic) features, and the anatomical structure (area) is influenced by growing conditions.

Adverse, arid conditions contributed to the decrease of the leaf area in all studied samples: varieties average of $13.79 \mathrm{~cm}^{2}$ in 2014 , compared to $2016-15.17 \mathrm{~cm}^{2}$ (Table 3).

Table 3. The area of the leaf surface of the red currant varieties.

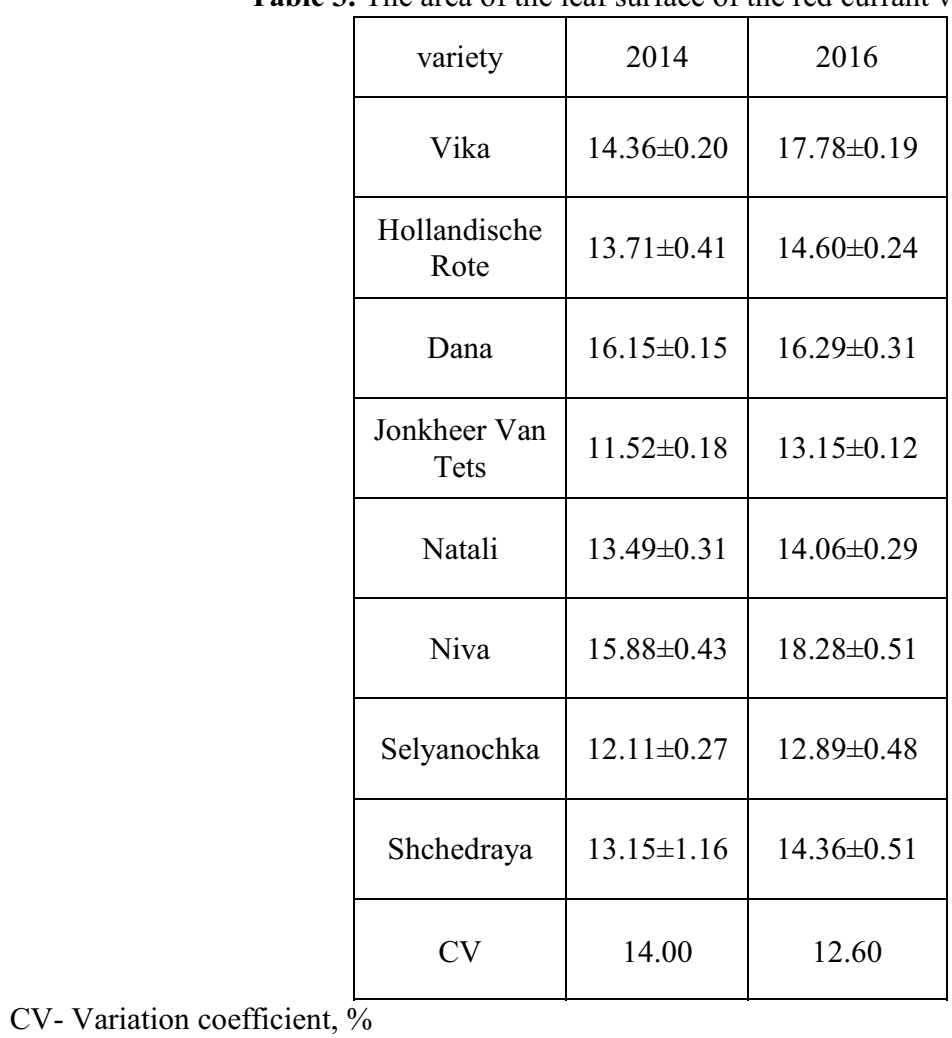

The reason for this decrease is a decrease in cell growth, a decrease in transpiration level, and in the future already in July leaf cast and a decrease in the annual shoots growth, 
which is a certain strategy to preserve moisture for plants. It is known that adaptability to water stress in perennial plants is ensured by combining strategies: escaping drought, drought avoidance and tolerance to it $[24,25]$. The methods considered in this paper are applicable to the assessment of biological and agronomic adaptation. With this, biological adaptation of plants is of greater importance when introduced to other regions, i.e. it is the stress load limit at which plants exercise the function of preserving the species as biological unit. For fruit and berry plants, yield and sustainability is a "trade-off" that plants make during a period of stress. Agronomic sustainability is of great practical importance for intensive gardening. Because it reflects the degree of yield reduction due to the stress effects of the environment and is expressed in the measurement shares of plant productivity changes due to stress [26]. In our experiment, all varieties of red currants under stress have reduced their yield by an average of $32 \%$ compared to optimal conditions (Table 4 ).

Table 4. Yield of red currant varieties

\begin{tabular}{|c|c|c|c|}
\hline variety & 2014 & 2016 & decrease $\%$ \\
\hline Vika & $8.40 \pm 0.69$ & $11.97 \pm 1.02$ & 30 \\
\hline $\begin{array}{l}\text { Hollandische } \\
\text { Rote }\end{array}$ & $7.90 \pm 0.62$ & $10.50 \pm 0.53$ & 25 \\
\hline Dana & $10.50 \pm 0.21$ & $15.80 \pm 0.46$ & 33 \\
\hline $\begin{array}{c}\text { Jonkheer Van } \\
\text { Tets }\end{array}$ & $5.60 \pm 0.41$ & $7.91 \pm 0.92$ & 29 \\
\hline Natali & $6.75 \pm 1.61$ & $8.95 \pm 0.59$ & 24 \\
\hline Niva & $11.20 \pm 0.71$ & $16.50 \pm 0.81$ & 32 \\
\hline Selyanochka & $4.20 \pm 0.91$ & $8.40 \pm 0.71$ & 50 \\
\hline Shchedraya & $5.20 \pm 0.57$ & $7.80 \pm 0.78$ & 33 \\
\hline $\mathrm{LSDp} \geq 0.05$ & 0.42 & 0.87 & \\
\hline
\end{tabular}

LSD-smallest significant difference

At the same time, the genotypes of Niva, Dana, Vika and Hollandische Rote, despite the decrease in yields, are consistently high-yielding varieties.

Laboratory studies during favorable and dry periods were fully consistent with field observations: bush habitus, marking assessment of flowering and fruiting, number of annual increases, and null shoots (or innovations). 


\section{Conclusions}

Practical value of physiological and morphological methods of research is due to reliable compatibility with natural (field) stability, possibility of analysis at the early development stages of plants and in short terms, confirmation by methods of statistical analysis, a clear distinction on studied indicators of red currant varieties of different genetic origin. The varieties Dana, Niva, Vika, Hollandische Rote are promising for introduction and industrial cultivation for intensive gardening. The studied varieties during dry periods are able to regulate metabolism by regulating water deficit, fractional composition of water, leaf surface area. Use in the production of Natali, Shchedraya and Jonkheer Van Tets varieties is possible with the use of artificial irrigation. Selyanochka variety is most affected by weather conditions and is recommended to be grown in temperate climate area.

\section{References}

1. I.P. Khaustovich, Y.A. Solovyova, G.N. Pugachev, Development Problems of Regional Agro-industrial Complex, 2 (18), 31-35 (2014)

2. N.I. Savelyev, A.N. Yushkov, et al., Genetic potential of fruit crops resistance to abiotic stressors, 212 (Michurinsk, 2010)

3. N.R. Bzhetseva, S.M. Tulparova, M.D. Shekhmirzova, Influence of weather conditions on the state of water regime of currant plants In coll.: Actual issues of science and education materials of international scientific - practical conference, 25-29 (2019)

4. O.V. Panfilova, O.D. Golyaeva, Agricultural Biology, 52 (5), 1056-1064 (2017) doi.org: 10.15389/agrobiology.2017.5. 1056

5. K. Neeru, B. Kalpna, H. M. S. Kadambot, N. Harsh, Cogent Food \& Agriculture, 2, 271-313 (2016), doi.org: 10.1080/23311932.2015.1134380

6. R.R. Wise, A.J. Olson, S.M. Schrader, T.D. Sharkey, Plant Cell Environ., 6 (27), $717-$ 724 (2004) doi: 10.1111/j.1365-3040.2004.01171.x

7. N.I. Nenko, G.K. Kiseleva, E.V. Ulyanovskaya, E.K. Yablonskaya, A.V. Karavayeva, Agricultural Biology, 54, 1, 158-168 (2019) doi.org: 10.15389/agrobiology.2019.1.158rus

8. N.I. Nenko, I.A. Ilina, V.C. Petrov, M.A. Sundireva, E.K. Yablonskay, Research Journal of Pharmaceutical, Biological and Chemical Sciences, 10 (1), 1903-1910 (2019)

9. Yu.I. Chirkov, Agrometeorology, 256 (Hydrometeoizdat, Leningrad, 1986)

10.G.V. Udovenko, Diagnostics of plant resistance to stress exposures, 230 (Methodological guide, VIR, Leningrad, 1988)

11. M. D. Kushnirenko, E.A. Goncharova, G. P. Kurchatova, Methods of comparative determination of drought resistance of fruit plants, In monograph Methods of estimation of plants resistance to non-favorable conditions of environment, 87-101 (1976)

12. S.S. Baslavskaya, O.M. Trubetskova, Workshop on plant physiology, 328 (Moscow, 1964)

13. S.A. Tarasenko, E.I. Doroshkevich, Workshop on physiology and biochemistry, 122 (Practical Manual, Oblizdat, Grodno, 1995)

14. N. Draper, H. Smith, Applied Regression Analysis, 3 Edition, John Wiley \& Sons Inc, 912 (2016).

15. O.V. Panfilova, O.D. Golyaeva, S.D. Knyazev and O.V. Kalinina, Physiological Features of Red Currant Adaptation to Drought and High Air Temperatures, Drought - 
Detection and Solutions, 195-207, (Gabrijel Ondrasek, IntechOpen, 2019) DOI: 10.5772 /intechopen. 85033

16. Repkina N.S., Ecological and physiological study of adaptation mechanisms of wheat plants to separate and joint action of low temperature and cadmium, 24 (Petrozavodsk, 2014)

17. A. Sękara, R. Bączek-Kwinta, M. Gawęda, A. Kalisz, R. Pokluda, A. Jezdinský, Hort. Sci. (Prague), 43 (3), 149-157 (2016) doi: 10.17221/162/2015-HORTSCI

18. O.V. Panfilova, S.D. Knyazev, O.D. Golyaeva, O.V. Kalinina, Bulgarian Journal of Agricultural Science, 1, (2021) (to be published)

19. V.P. Krivoruchko, Ecological and biological bases of increasing productivity of apple orchards of northern Kyrgyzstan, 224 (Bishkek, 1998)

20. L.M. Mazorra, M. Nunes, E. Echerarria, F. Coll, M.J. Sanches-Blanco, Biologia Plantarum, 45, 593-596 (2002) doi: 10.1023/A:1022390917656

21. H. Omae, A. Kumar, M. Shono, Journal of Botany, 2012 (2012) doi: $10.1155 / 2012 / 803413$

22. M.D. Kusnirenko, Physiology of water exchange and drought resistance of fruit plants, 216 (Știința, Chisinau, 1975)

23. S. Machado, G.M. Paulsen, Plant Soil, 233 (2), 179-187 (2001) doi: 10.1023/A:1010346601643

24. M.M. Chaves, J.P. Maroco, J.S. Pereire, Functional Plant Biology, 30, 239-264 (2003)

25. A.V. Rudikovskiy, E. G. Rudikovskaya, L. V. Dudareva, O. N. Potemkin, Contemporary Problems of Ecology, 3, 422-430 (2015)

26. E.A. Goncharova, Agricultural Biology, 1, 24-31 (2011) 